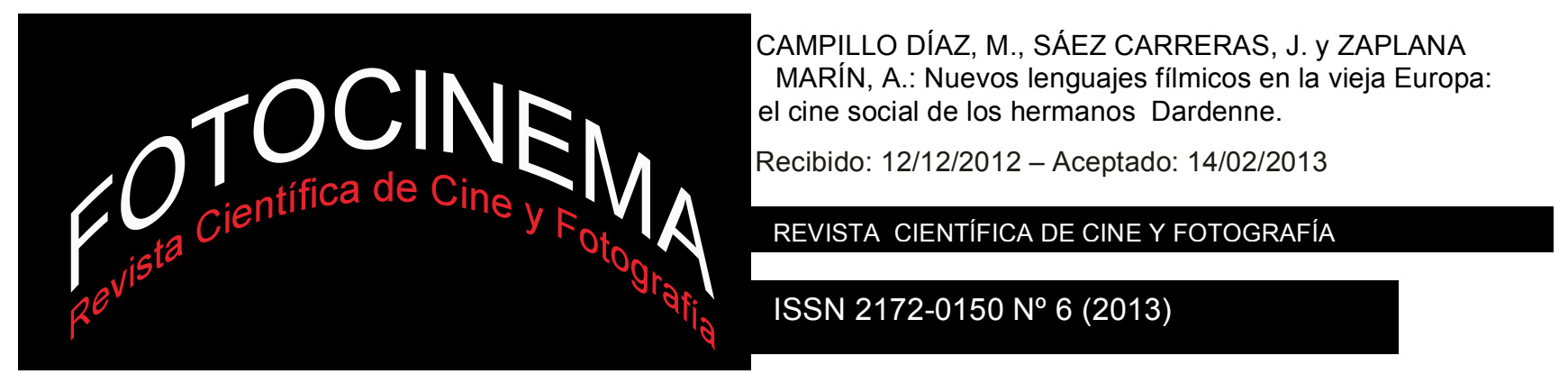

\title{
NUEVOS LENGUAJES FÍLMICOS EN LA VIEJA EUROPA: EL CINE SOCIAL DE LOS HERMANOS DARDENNE
}

\section{NEW CINEMATOGRAPHIC LANGUAGES IN OLD EUROPA: DARDENNE BROTHERS SOCIAL FILM}

\author{
Margarita Campillo Díaz, Juan Sáez Carreras y \\ Andrés Zaplana Marín \\ Universidad de Murcia
}

\begin{abstract}
Resumen:
Las películas de los hermanos Dardenne son documentos vivos, poblados de personajes marginales y excluidos, que ofrecen enormes posibilidades para reflexionar desde múltiples espacios educativos. Su obra presenta un reconocido estilo personal autoral, tanto en la forma como en las historias que aborda, susceptible de análisis y profundización. Adentrarse en ella y bucear su estilo narrativo es el objetivo de este estudio. Para materializarlo se esboza, al inicio, la tradición europea creadora de nuevas formas de expresión fílmica a lo largo del siglo XX -desde el naturalismo poético francés hasta llegar al movimiento nórdico “Dogma 95”- para explorar, más detenidamente, a continuación la producción de los directores belgas: siguiendo un planteamiento evolutivo que transita desde sus primeros trabajos que antecederán a "La promesa" (1996) hasta su último film, "El niño de la bicicleta"( 2011), en este texto se analizan las obras de ficción de los hermanos y el estilo característico que predomina en ellas. Planos cortos, que transmiten su propia vida interior, y de larga duración para que se pueda seguir atentamente la acción, filmación continuada en el mismo orden programado en el guión, ausencia de música intrusiva, imágenes despojadas de toda clase de buenos sentimientos... el sello personal de los Dardenne abre cauces novedosos de expresión comunicativa tan poderosos como creativos.
\end{abstract}

Palabras clave:

Cine; historia del cine; análisis fílmico; narrativa audiovisual; exclusión social

Key words:

Cinema; cinema history; film analysis; audiovisual narration; social exclusion 
"El rodaje supone una organización minuciosa donde la libertad debe llegar de una cierta manera".

Hnos. Dardenne

\section{Contextualización, objetivos $y$ metodología: contenido $y$ lenguaje en la obra de los hermanos Dardenne}

\subsection{Tradición y lenguaje: algunos antecedentes de la obra fílmica de los Dardenne}

A modo de introducción y ánimo contextualizador merece la pena apuntar, sin intenciones profundizadoras ya que no es el objeto de esta exploración, algunos de los principales movimientos fílmicos surgidos en nuestro viejo continente en los que los hermanos Dardenne se sentirían sin esfuerzo ubicados, como en algunos casos ellos mismos han tenido la oportunidad de aclarar. Este somero esbozo presenta para nosotros una doble virtualidad. Por un lado, nos permite confirmar una vez más que gran parte de los procesos de renovación del lenguaje cinematográfico han tenido su origen en Europa y, por otro, lo que más interesa a nuestros fines, intenta denotar como buena parte de esas vanguardias han influido decisivamente en muchos cineastas actuales, y muy especialmente en la importante obra de ficción de los hermanos Dardenne, en la cual, en uno de sus aspectos particulares, se centra el presente trabajo. Buena parte de los estudiosos del cine de los Dardenne, por no decir en su conjunto a falta de conocer todas las opiniones, sitúan la obra de los autores belgas en la tradición que ha combatido por la renovación del lenguaje en la realización de las películas, por la innovación de nuevos lenguajes con los que los creadores poder expresar sus ideas.

Efectivamente, aunque las industrias cinematográficas más poderosas del planeta no se encuentran en el continente europeo (el llamado Hollywood norteamericano y el también denominado, por comparación, Bollywood indio son desde hace años las más potentes), el cine, sin embargo, nació en Europa y aquí es donde se han producido los más importantes desarrollos estéticos del séptimo arte. Ya desde la época del cine silente, la factoría "hollywoodiense" ha sido consciente de ello y ha tratado de captar a los más

98 
importantes directores europeos. Así, cineastas como Victor Sjöstrom, Friedrich W. Murnau, Fritz Lang, Ernst Lubitsch, Jean Renoir y Alfred Hitchcock, entre otros muchos autores ya consagrados en la historia del cine, dieron brillo y esplendor a las mejores décadas de la industria estadounidense, creando estilos y formas de relatar que supusieron una ruptura con los modos convencionales aceptados de contar historias a través de las imágenes. La lista es muy amplia y ateniéndonos a este declarado espíritu impresionista podemos insistir en el repaso formulado líneas más arriba.

Así, centrándonos en las más conocidas, entre las grandes corrientes europeas de la narración fílmica (las primeras vanguardias cinematográficas nacieron también en el viejo continente), destaca una evidente tendencia hacia el realismo. De esta forma, a comienzos de los años treinta del siglo XX, con el sonido como nuevo aditamento del lenguaje fílmico, surge el naturalismo poético francés, cuyos principales valedores fueron Jean Vigo, René Clair, Jean Renoir, Jacques Feyder y Marcel Carné. En la década siguiente, encontramos otro hito europeo en el desarrollo del lenguaje cinematográfico: el neorrealismo italiano, una especie de realismo que "consigue algo tan difícil como que la ficción organizada por el artista parezca documental, reportaje directo" (Gubern, 1989: 288), cuyo ejemplo paradigmático vendría representado por el filme Roma, ciudad abierta (Roma, citta aperta, 1945) de Roberto Rossellini. Dentro de este movimiento destacaron también Vittorio de Sica y Luchino Visconti. Los directores Michelangelo Antonioni y Federico Fellini, aparecieron ya en la fase postneorrealista y buscaron, luego, aunque de formas diferentes, nuevos cauces expresivos.

A finales de la década de los cincuenta y, sobre todo, durante los años sesenta, se produce la eclosión de los "nuevos cines", donde, a diferencia de lo que se consideraba correcto hasta entonces, la cámara se hace presente, a veces casi como un personaje más. El autor el director de la película, será ahora quien unifique idea e imagen en la llamada "puesta en escena", en el intento de configurar al cine como el arte por antonomasia del siglo XX. En 
Francia, aparece la "nouvelle vague" con autores como François Truffaut, Jean-Luc Godard, Alain Resnais, Claude Chabrol y Eric Rohmer ; en Gran Bretaña surge el "free cinema" con los llamados "jóvenes airados": Lindsay Anderson, Karel Reisz, Tony Richardson y Jack Clayton, entre otros; autores como Volker Schlöndorff, Werner Herzog, Wim Wenders o Rainer W. Fassbinder dieron lugar al llamado "nuevo cine alemán”; en Italia, el "cinema nuevo" fue, sobre todo en sus inicios un cine fuertemente comprometido política y socialmente, con cineastas de la talla de Bernardo Bertolucci, Pier Paolo Pasolini, Marco Ferreri y Ermanno Olmi; en España, las denominadas "Conversaciones de Salamanca" en 1955 fueron el punto de partida de una nueva generación de cineastas (el denominado "nuevo cine español”). De esta forma, Carlos Saura, José Luís Borau, Basilio Martín Patino, Víctor Erice y Vicente Aranda, entre otros, dieron un auge inesperado a un cine lastrado durante demasiado tiempo por la férrea censura impuesta por la dictadura franquista; por último, algo similar ocurrió en los países del Este, donde se empezó a denotar una cierta revolución estética contra la burocracia comunista. En este sentido, destacan los polacos Andrzej Wajda, Jerzy Kawalerowicz y Roman Polanski, los checos Milos Forman y Jiri Menzel, el yugoslavo Dusan Makavejev, los húngaros Miklos Jancsó e István Szabo y el ruso Andrei Tarkovski. La nómina de autores que durante estos años, consciente o inconscientemente, van a contribuir a la utilización de lenguajes que fecundarán los estilos de hacer cine, desde entonces ahora, no cesará de aumentar. El cine ya tiene conseguido con todo derecho la adjetivación de ser un arte que no solo divierte sino que también nos hace pensar (Badiou, 2004), como un instrumento filosófico, sobre los distintas realidades culturales y distintos problemas que los humanos, en sus diferentes relaciones, presentan. Y no solo en el cine europeo y norteamericano sino en otras geografías más alejadas como la latinoamericana, la asiática y africana. Muchas citas de directores y películas podrían ser citadas en estas páginas provenientes de estas culturas, pero seguiremos centrándonos en nuestra compleja y "tradicional” Europa, cargada de cultura y amante del cine de autor, como muestran los grandes festivales cinematográficos (Berlín, Venecia, Cannes, San Sebastián, Huelva, Sitges...). 
Así, al celebrarse los cien años del nacimiento del arte fílmico, en nuestros noventa, surge, impulsado por el cineasta nórdico Lars von Trier, un controvertido movimiento, denominado "Dogma 95”, que recoge, en cierta manera, alguno de los postulados de los “nuevos cines" de los años sesenta, en forma de un decálogo, donde sobresalen especialmente dos de los "mandamientos" que más reivindican sus defensores : la filmación con la cámara al hombro y la prohibición del uso de cualquier tipo de música incidental, lo que nos remite claramente, salvando las distancias sintácticas y semánticas que las hay, al cine de los Dardenne. En el cine europeo de principios del siglo XXI (Imbert, 2010: 625), las diferencias entre cine documental y de ficción se han reducido al mínimo, hasta casi confundirse. Imbert señala cuatro razones principales para explicar este fenómeno que tanto tiene que ver con los lenguajes fílmicos:

- La crisis del relato clásico y de las formas institucionales de representación.

- Un retorno hacia "lo real", hacia el reportaje directo (lo "hipervisible").

- Una búsqueda de la inmediatez, forjada por los nuevos adalides de la "cyberrealidad": Facebook, Twitter, YouTube,...

- La utilización de un estilo eminentemente "observacional" (montaje discontinuo, cámara al hombro...).

En suma, cine "indi”, iraní, rumano, japonés y chino, alemán y austriaco, británico y USA, canadiense, francés e italiano, español y portugués...,con nombres y filmografías muy identificadas ,en obras mayores y menores, de planteamientos más o menos transgresores en sus propuestas, en el campo de la comedia, el drama, el thriller, el cine político, o simplemente de aventuras, por solo citar algunos ejemplos de una amplia clasificación de géneros, diseccionando perfiles humanos, hechos, instituciones y hábitos tanto como cantando a la vida y a los hombres...el mundo en que se mueve el cine es ya un universal, un escenario de creación de lenguajes, de formas de expresión, que sigue fascinando a sus más , y menos, adictos seguidores. En este escenario de creación, de tradición y ruptura, cabe situar a los hermanos Dardenne cuando nos remitimos a su obra. 


\subsection{Objetivos y metodología}

El objetivo, pues, de esta colaboración es el de poner de relieve la importancia de la obra fílmica de los Dardenne, en general y, en particular, el estilo narrativo que caracteriza sus películas, en dónde forma y fondo, contenido y lenguaje para expresarlo, se aúnan de modo impecable para dar lugar a una obra tan singular como comprometida "con la acción social”, tal y como ha mostrado Michéle Bissiére (2013).

Para llevar a cabo esta meta se utilizan varias metodologías acorde con los diversos objetivos que se desean lograr. Por una parte, se utiliza una metodología evolutiva para llevar a cabo el análisis de las obras que de modo cronológico, desde "La promesa" a su último film, "El niño de la bicicleta", han realizado los hermanos Dardenne. Esta metodología histórica es, por otra parte, conjugada con la analítica de escenas e imágenes creando las condiciones para la reflexión sobre ellas. Esto es, al tratarse de una exploración de carácter analítico-reflexivo, se estudian sus películas, tanto en sus aspectos formales como temáticos, con vistas a ahondar no solo en los capitales temas humanos y sociales propuestos en ellas, y que pueden ayudar a explicar el discurrir errático y disfuncional de las sociedades europeas contemporáneas, sino también en como los hermanos belgas han ido conformando su peculiar estilo cinematográfico. A tal efecto, se han descrito con detalle, a lo largo del texto, una serie de secuencias que los autores han considerado singularmente significativas. En este sentido se utiliza una metodología de contraste y comparación al describir en cada film, destacando la escena que hemos creído más pertinente, el ajuste temático y formal que los autores belgas dan a sus películas en un esfuerzo notable de realismo, naturalidad y sencillez expresiva, a nuestro juicio innovador que los conecta decididamente a la tradición creadora y transgresora apuntada en el apartado anterior. De ahí que nos parezca interesante destacar como, en cada una de sus realizaciones, los puntos fundamentales que caracterizan su modo de hacer cine se adecuan muy flexiblemente a las historias que desean narrar. Este modo de entender su cine ha dado lugar a críticas de diverso signo, 
enfatizando por parte de los discordes con su obra, el hecho de que los Dardenne sostengan una "creencia estética problemática, tal y como la que confiere a un arte las propiedades de los temas, las materias que el autor incluye o tiene en cuenta" (Ranciére, 1999: 110). Esta característica fundamental que algunos estudiosos dicen atravesar sus films convertiría la pobreza- he aquí la fuerza de la semántica- en arte realista, del mismo modo que novelas como Germinal de Zola y Madame Bovary de Flaubert son adjetivadas con similar rótulo.

\section{El cine de los Hermanos Dardenne: naturalismo, continuidad y realismo}

Bélgica es un país que posee tres comunidades lingüísticas diferenciadas. Ello hace que su cine se realice, la mayoría de las veces, en forma de coproducción con uno o varios países vecinos, sobre todo con Francia, Alemania y Holanda. Valonia-Bruselas es la comunidad francófona que ha dado cineastas tan interesantes como el ya mencionado Jacques Feyder y, en los últimos años, André Delvaux, Chantal Akerman, Gerard Corbieu o los hermanos JeanPierre y Luc Dardenne.

Cuando los Dardenne deciden pasarse en 1987 al cine de ficción, ya han completado una extensa y variada carrera en el campo del cine documental. $\mathrm{Su}$ estilo en este terreno hunde sus raíces en el llamado "cine-ojo" del realizador soviético Dziga Vertov y en el "cinema verité" francés de los sesenta. Sus trabajos son testimonios sociales de una época donde, al mismo tiempo que se producían duros ajustes laborales por los llamados procesos de "reconversión industrial”, la Unión Europea, cuya principal sede administrativa es precisamente la capital belga, parecía empezar a consolidarse con la entrada de nuevos países miembros. Una de las localidades víctima de aquellos “ajustes” fue Seraing, una ciudad minera e industrial a las afueras de Lieja, donde los cineastas pasaron su infancia. El paisaje devastado de esta ciudad con sus fábricas, chimeneas y solares abandonados, es el telón de fondo utilizado por los hermanos en buena parte de sus largometrajes de ficción. El cambio en la manera de realizar películas 
se ha producido, ya que los Dardenne "se decidieron entonces a realizar obras más personales, reflejando su visión de la sociedad y sus preocupaciones estéticas" (Bissiére, 2013: 1); proceso en el que otros, como Madeleine Arnot, no verían sino una cierta continuidad al propiciar, por parte de nuestros autores "el paso de una puesta en escena de lo colectivo en crisis a la ficcionalización de las crisis individuales” (Bissiére, 2013: 2).

\subsection{Estilo directo, verosimilitud y realismo cotidiano}

\subsubsection{La promesa o el cine sin concesiones}

En su libro, a modo de diario, Luc Dardenne (2006) reconoce que las dos primeras películas de ficción: Falsch (1987) y Je pense à vous (1992), realizadas junto a su hermano Jean-Pierre, fueron intentos fallidos en la búsqueda de un estilo propio, que empezaría a tomar carta de naturaleza con su siguiente obra, La promesa (La promesse, 1996), que obtuvo la Espiga de Oro en la Seminci de Valladolid. Filmado en Seraing, el filme supone un aldabonazo, desde el punto de vista del contenido, a la dormida conciencia europea de finales del siglo XX, incapaz al parecer de atajar las nuevas formas de esclavismo que surgen en sus mismas narices. Las personas inmigrantes llegadas a los países de Europa Occidental en las últimas décadas han sido generalmente objeto de un doble proceso de victimización. Primero, han sufrido terribles situaciones de miseria en sus países de origen, propiciadas, en muchos casos, por las naciones del "primer mundo" y luego, cuando después de grandes penalidades han conseguido llegar al país de acogida, han sido víctimas de redes mafiosas de diverso tipo, que les prometen conseguir los papeles necesarios para legalizar su situación a cambio de fuertes sumas de dinero, mientras les mantienen ocultos en viviendas abandonadas y en condiciones infrahumanas (García, 2007). Así actúa el pequeño grupo de explotadores de nuevo cuño compuesto por Roger (Olivier Gourmet) y su hijo adolescente, Igor (Jérémie Renier), en un país como Bélgica, de deleznable pasado colonial. El fortuito accidente mortal sufrido por Hamidou (Rasmané Ouedraogo), un inmigrante de Burkina Faso, 
supondrá un distanciamiento cada vez mayor entre el joven y el “padre-ogro” (Lalanne, 1996).

Como los directores neorrealistas de los cuarenta, Jean-Pierre y Luc Dardenne pretenden mostrar, desde el punto de vista sintáctico, con la mayor verosimilitud posible, la realidad cotidiana, aquello que acontece frente a nosotros mismos, y que tantas veces dejamos conscientemente de mirar. Y lo hacen de la forma más natural posible, con un estilo formal directo, sin imposturas ni manipulaciones técnicas o estéticas. De ahí la filmación cámara en mano o la ausencia de música intrusiva. En sus imágenes late una contundente representación social de los más desfavorecidos, despojada de toda clase de buenos sentimientos o prejuicios morales. Se deja vía libre para que sea cada espectador el que interponga, si es posible, algún tipo de solución al dilema moral planteado.

Por eso no existe en La promesa, ni tampoco en sus trabajos posteriores, el clásico "happy end" del cine clásico estadounidense. La película concluye con un final abierto y desesperanzador, aún a pesar del intento de redención del chico protagonista: Igor confiesa a Assita (Assita Ouedraogo) la terrible verdad sobre su marido, pero no se atreve a hacerlo de frente, sino cuando la mujer está subiendo las escaleras de la estación ferroviaria donde iba a coger ese tren a ninguna parte. La cámara filma la espalda de la mujer, mientras Igor, que no ha llegado a subir ningún escalón, se atreve por fin a contar lo sucedido. Cuando termina de hablar, la cámara se mueve, sin corte, hacia él, en primer plano y con la cabeza agachada. Un nuevo movimiento nos lleva hacia la mujer, que sigue de espaldas con su bebé a cuestas, mientras se mantiene el silencio, sólo roto por los ruidos de trenes a lo lejos. La mujer se quita el gorro de la cabeza, se vuelve y pasa junto al muchacho. Entrecruzan sendas miradas y Assita sale del plano dejando a Igor aislado. La cámara nos muestra un plano general (el último del filme) de un pasillo de la estación por donde la mujer con su bebé ha emprendido el camino de vuelta. Entonces el chico sale corriendo tras ella, se pone a su lado y se pierden en la lejanía, mientras empiezan a aparecer los títulos de crédito. Quizá haya sido el reconocido crítico Ángel Fernández Santos, quien, en sus últimos años de 
vida y profesión (murió en 2004) y desde las páginas del periódico "El País”, más certeramente consiguiera expresar el sentido último de este primer gran largometraje de los hermanos belgas. Así terminaba el desaparecido periodista su espléndido comentario, que a día de hoy resulta terriblemente premonitorio: "un filme necesario para quienes quieran contribuir a despejar nubarrones de algo innombrable que se nos echa encima a los europeos libres mientras sesteamos" (Fernández, 1997).

\subsubsection{Rosetta o la niña coraje obsesionada por el empleo}

Sus dos siguientes trabajos: Rosetta (Rosetta, 1999) y El hijo (Le fils, 2002) suponen, en el plano formal, un importante punto de inflexión. En ambas, la cámara se coloca tan cerca de los respectivos personajes protagonistas, (Rosetta y Olivier), que parece como si estuviese persiguiéndoles. La inquietud, el desánimo y la zozobra de estos dos seres en continuo estado de aislamiento se han transmitido a la máquina de filmar, como si ésta fuese en realidad una prolongación de los propios personajes. Lo importante aquí reside en el retrato del individuo, no como representante de una cierta clase social, sino como sujeto en sí mismo. Lo esencial es mostrar su conducta, pero despojada de cualquier artificio moralizante; es decir, sin justificarla ni rechazarla, pero captándola de forma directa y natural.

Rosetta supuso el primer gran éxito de los hermanos Dardenne, pues además de obtener en el Festival de Cannes dos grandes premios: la Palma de Oro y el de interpretación femenina para su protagonista, Emile Dequenne, propició tan amplio debate en todos los aspectos, que el gobierno belga promulgó a finales de ese mismo año (1999) un plan de empleo que se conoció como "Plan Rosetta". La protagonista del filme está lejos de la visión, a menudo, demasiado "comprensiva" de los desempleados que pueblan las películas de directores del llamado "cine social” como el británico Ken Loach o el español Fernando León de Aranoa. Tampoco nos encontramos ante una heroína de la clase obrera como la protagonista de Norma Rae (1979) de Martin Ritt. Si buscamos un antecedente del personaje “dardenniano" quizá lo encontraríamos en Mouchette (Mouchette, 1967) de Robert Bresson. 
Rosetta sería entonces una "Mouchette" actual, transplantada desde el insalubre entorno rural de su época al universo urbano y hostil de finales del siglo veinte. Como la muchacha "bressoniana", Rosetta es una adolescente resentida, solitaria y desamparada. Su único objetivo es la conquista de un empleo que propicie su integración en el depredador sistema capitalista contemporáneo, todo ello sin importarle lo que quede en el camino. Su posible liberación parece iniciarse al final del trayecto cuando parece comprender que la independencia y el desarrollo personal sólo se consiguen fuera de las esferas de poder. Así la describe Ranciére (1999: 112), el filósofo francés: "Rosetta es una 'Hija Coraje', que testimonia la deshumanización a la que una sociedad obliga a los seres humanos. Y el movimiento perpetuo con el que la película nos pega contra su cuerpo exacerba el gesto clásico del militante o del sociólogo, obligándonos a compartir la experiencia sensorial del habitante de este mundo tan cercano que quisiéramos no ver”.

En su diario, Luc Dardenne (2006:84) anota la declaración de intenciones que debía acompañar al guión ya terminado de la película, antes de comenzar su filmación: "Es una película de guerra. (..) Filmaremos el cuerpo de Rosetta al borde de la explosión, comprimido, tenso. (..) Nuestra cámara nunca la dejará en paz, intentando ver, incluso aunque sea invisible, la noche en que Rosetta se debate".

A este respecto Guffanti (2013: 2) hace énfasis en lo que él llama "la cámara nerviosa", la cámara que se mueve continuamente, "como uno de los componentes distintivos del estilo de los Dardenne”.

\subsection{La preocupación por las infancias y la necesidad de vínculos}

El interés por la infancia ha sido una cierta constante en nuestros intereses investigadores (Campillo, 2007, 2012; Sáez, 2007; Zaplana, 2007 y 2005), llegando en su momento a adentrarnos especialmente en la obra de los Dardenne (Sáez, 2012) con motivo de su última obra, El niño de la bicicleta. Esta colaboración propicia que profundicemos en una filmografía que desde sus inicios se la preocupado por ese ignoto que son los niños. 


\subsubsection{El hijo o la incertidumbre moral}

Algunos inusitados episodios de violencia infantil sacudieron las conciencias europeas en aquellos años. Quizá ninguno tanto como el asesinato de un pequeño británico de dos años a manos de otros dos niños de diez. En El hïo, poco a poco, iremos sabiendo que Olivier, el maestro de carpintería de un centro de reinserción para jóvenes, tuvo un hijo pequeño que fue asesinado por otro niño de once años. A esa escuela llega entonces un adolescente, Francis (Morgan Marinne), a quien el protagonista cree reconocer como el asesino de su hijo. Aquí, la cámara se coloca de nuevo junto a este hombre desgarrado, persiguiéndole sin cesar para mostrar, en una suerte de "fisicidad" extrema, el alto grado de tensión íntima que le corroe, sobre todo a partir de que se convierte en tutor del joven. Así lo expresa Luc: "Filmar a Olivier de espaldas, filmar su espalda, su nuca, es sin duda la forma que hemos encontrado para dejar hablar y oír a ese alguien, ese movimiento imposible de interpretar, inconsciente hacia Francis” (Dardenne, 2006: 140).

El muchacho intenta buscar un vínculo afectivo con su maestro (quizá como sustituto del padre que probablemente nunca tuvo), mientras el hombre de mirada hundida y extraviada parece buscar explicaciones en el comportamiento del chico que cercenó su discurrir vital. Se establece entonces una honesta y extraña dialéctica entre estos dos seres heridos que, al no estar seguros el uno del otro, pasan buena parte del tiempo midiendo la distancia que los separa (extraordinaria la secuencia en que el muchacho prueba la habilidad de su maestro para determinar a ojo las longitudes entre objetos). La película, como apunta Quintana (2002), cobra la forma de una especie de duelo místico donde el dilema abre dos alternativas posibles: la venganza o el perdón. Es una cuestión humana ampliamente debatida, que también el cine ha hecho suya. Recordemos una película reciente, La vida en tiempos de guerra (Life during wartime, 2009) de Todd Solondz. En ella un personaje se pregunta: "Si es posible perdonar y olvidar, o es posible perdonar y no olvidar, ¿no es mejor olvidar aunque no perdones?”. Realmente, como parecen decirnos los hermanos Dardenne, Olivier no ha 
encontrado opción alguna que le satisfaga plenamente, pero ha empezado a cerrar su herida moral, pues su decisión final ha tenido una dimensión ética, de acuerdo con las razones que esgrimen Schujman e Iglesias (2013) tiene un carácter personal, se adopta en un contexto de ambivalencia e incertidumbre, se asume la responsabilidad frente al otro sin esperar contrapartida alguna y, por último, tiene el carácter de una apuesta, es decir, se actúa en soledad sin poder adelantar las consecuencias posteriores.

El hijo fue la última película de los Dardenne que Fernández Santos pudo ver. Así terminaba el reconocido crítico su comentario sobre el filme: "más brotes de la encendida, volcánica verdad que se mueve en las tripas de este nuevo, y nuevamente lleno de radicalidad, filme de los creadores de "La promesa" y "Rosetta", otras dos joyas fundacionales del nuevo y regenerador impulso realista del cine europeo” (Fernández, 2002). El largometraje obtuvo en Cannes un nuevo premio: el de mejor interpretación masculina para Olivier Gourmet, el actor "fetiche" de los hermanos Dardenne, pues ha aparecido hasta ahora en todas sus películas, a partir de La promesa.

\subsubsection{El niño o las respuestas imposibles de un padre}

$\mathrm{Si}$, como los hermanos cineastas han manifestado en varias entrevistas, $\mathrm{El}$ hijo podría haberse titulado El padre, en referencia al personaje principal, el título de su siguiente largometraje: El niño (L'enfant, 2005), no sabemos muy bien a quien se refiere: al bebé de Bruno y Sonia, o al propio Bruno, infausto padre de la criatura. Cuenta Luc Dardenne que, una vez tomada la decisión de que fuese Jérémie Renier quien interpretase a Bruno, le llamaron para que decidiese cual iba a ser su apellido en el filme. El actor respondió enseguida: Michaux, es decir, el mismo apellido de Igor, su personaje adolescente en La promesa. Seguramente el intérprete, después de leer el guión, llegó a pensar que aquel personaje podría haberse convertido, con el paso de los años, en ese padre capaz de vender a su recién nacido por un fajo de billetes.

A nivel formal, este filme, también ganador de la Palma de Oro en el Festival de Cannes, presenta un formato más abierto en cuanto a la filmación de los 109 
personajes, a los cuales se les concede más libertad, pues el encuadre fílmico de la cámara se amplia y sus movimientos son algo más reposados. A pesar de ello, podemos observar el característico estilo narrativo de los Dardenne en momentos como el de la secuencia de la persecución de Bruno y Steve, su joven compañero de correrías. Ahora la cámara se distancia más del protagonista, porque al personaje parece como su conciencia le hubiese abandonado (es capaz de "trapichear" con el bebé como si fuese una mercancía más), mientras que en $E l$ hijo, la cámara podría asimilarse al espíritu del niño asesinado que acompaña al atormentado padre en su peripecia vital a la búsqueda de respuestas imposibles. De esta manera, vemos que tanto la historia que se cuenta como la percepción de los cineastas sobre la misma, son los factores determinantes de la mayor o menor apertura del encuadre fílmico y de los movimientos de cámara.

Es quizá por ello que las películas de los hermanos Dardenne tienen un efecto casi naturalista, que hacen pensar en una cierta improvisación. Nada más lejos de la realidad, pues la repetición de tomas hasta que el plano transmite su propia vida interior es una de las señas de identidad del cine "dardenniano", que son de los pocos directores actuales que filman en continuidad, es decir en el mismo orden que siguen las secuencias en el guión. Este método, mucho más costoso que los habituales, redunda, según han manifestado los propios cineastas, en un mejor trabajo del equipo de filmación y, especialmente, en la mayor identificación de los actores con sus personajes. La historia de El niño se gestó, según han manifestado sus autores, mientras filmaban su anterior trabajo, al ver pasar a una joven empujando un cochecito de bebé de manera muy violenta. Por eso, los guiones previos conocieron títulos como "La chica del cochecito" o "El niño del cochecito", que aunque descartados finalmente, preludiaban la importancia que para la acción iba a tener este accesorio para transportar bebés. Como también lo iba a tener el teléfono móvil del protagonista. Todos los movimientos de Bruno, con o sin Sonia, con o sin bebé, empujando el cochecito de Jimmy, que tanto marcan el carácter del filme, serán el preludio de la larga secuencia en los minutos finales con el personaje empujando el scooter por un puente de Seraing, quizá el mismo que Igor con Assita 110 
cruzaron para llegar a la estación de ferrocarril. El rodaje de esta secuencia fundamental en $E l$ hijo podemos verlo con detalle en el valioso documental $E l$ "home cinema" de los hermanos Dardenne (2006) de Jean-Pierre Limosin.

\subsubsection{De Seraing a Lieja: cine, escenarios y homenajes}

Este título hace referencia a que los cinco largometrajes de ficción desde Je pense à vous hasta El hijo fueron filmados en la propia Seraing. Sin embargo, sus dos trabajos siguientes fueron rodados en la ciudad de Lieja. El primero de ellos es un maravilloso cortometraje de poco más de dos minutos de duración que forma parte del filme colectivo Chacun son cinema (2007), que tenía el expresivo subtítulo: "o esa sensación cuando las luces se apagan y empieza la película”, un encargo del director de Cannes a más de una treintena de directores del cine actual para conmemorar la sexagésima edición del festival. Esta pequeña obra maestra se titula En la oscuridad (Dans l'obscurite) y nos permitimos describirla a continuación:

Se oyen unos ruidos extraños, sordos, mientras un chico se arrastra sigilosamente por el suelo entre unas butacas rojas. El muchacho sigue moviéndose en el oscuro local. Se escuchan de fondo cencerros y el ladrido de un perro. El joven se detiene y retira cuidadosamente lo que parece ser un abrigo para acceder al bolso que hay en la butaca aledaña a otra ocupada por una mujer, de la que vemos su brazo. El chico abre silenciosamente la cremallera del bolso y entonces retira la mano, pues la mujer ha empezado a sollozar. Entonces la cámara enfoca en primer plano el rostro de la joven bañada en lágrimas. Se pasa una mano por la cara para intentar enjugarlas y luego mueve las manos hacia su derecha donde tiene el bolso. De repente, coge la mano del chico con ternura y se la lleva a la cara, mientras suena la música melancólica y los ruidos de la banda sonora del filme que está viendo. Acerca las manos a sus labios y se hace la oscuridad.

El final es, a juicio de todos los seguidores del cine de los Dardenne, muy conocido: aparecen los títulos de crédito, en donde entre otras cosas se nos informa que el extracto sonoro corresponde al largometraje de Robert Bresson, Al azar, Baltasar (Au hasard, Baltasar, 1966) y que los protagonistas han sido Emilie Dequenne (la protagonista de Rosetta) y 
Jérémie Segard (Steve en El niño). Se trata, a nuestro juicio, de un emocionante homenaje a las salas de cine y, más en concreto, al cineasta francés Robert Bresson, a través de una de sus obras más singulares, aunque el cortometraje posee el sello característico de los hermanos belgas.

\subsubsection{El silencio de Lorna o la culpabilidad que humaniza}

Luc Dardenne hablaba en su diario, a finales de 2002, cuando prácticamente acababan de estrenar El hïo, que su siguiente película podría estar basada en una historia en torno a una joven albanesa, que se casa con un yonqui belga para obtener la nacionalidad, estando por medio una mafia de inmigración ilegal. Ese proyecto se abandonó entonces y, aunque el diario publicado acaba a principios de 2005, es fácil deducir, al ver El silencio de Lorna (Le silence de Lorna, 2008), que fue retomado poco después. Los Dardenne vuelven a tratar el mismo tema que ya habían abordado en La promesa, pero ahora la protagonista es la joven albanesa, personaje bien distinto de Assita, la mujer inmigrante africana de aquella, que tenía un carácter más secundario. Por eso, el dilema lo afronta ahora Lorna, al saber que los mafiosos quieren deshacerse de su marido de conveniencia, el drogadicto Claudy, interpretado por Jérémie Renier. El final de la película es uno de los más contundentes y estimulantes del cine de los últimos años: Lorna sufre un embarazo psicológico, pues siente que realmente está esperando un hijo de Claudy, a pesar de que las pruebas médicas confirman lo contrario. Finalmente, logra escapar de una muerte segura a manos de la misma mafia para la que colaboró, al haberse convertido en un estorbo para sus planes, y alcanza una cabaña abandonada, donde empieza a comunicarse con su hijo imaginario. De alguna manera, la protagonista ha perdido su antigua identidad social y busca un vínculo afectivo (quizá el mismo que inició con Claudy, sin proponérselo siquiera) que la reconcilie consigo misma. Lorna no es, como Rosetta, una especie de "guerrera”, sino más bien una "estratega", una mujer mesurada, observadora y enigmática, que cambia sustancialmente al adentrarse en el mundo vulnerable del adicto Claudy Como otros protagonistas de los hermanos Dardenne, Lorna arrastra una culpabilidad 
interior que, a lo largo del relato, paradójicamente se abre a la vida y a los otros. Como dice Marsella (2013), "no existe el yo sin el otro: ahí reside la estrategia antropológica que subyace en todos sus filmes y la ética de este dúo de cineastas”.

También a nivel formal, este filme recuerda mucho a La promesa, sobre todo en ciertos momentos donde se trasluce en ambos una cierta estética que parece heredada del cine policíaco estadounidense de los años setenta (Lumet, Friedkin, etc.). A este respecto Luc Dardenne aclara "que hay elementos del género en Lorna como la intriga, la ciudad, la lluvia... Mantiene una cierta estética. Pero ni Lorna es una mujer fatal ni su vida va más allá de lo cotidiano y banal. Nos preocupa el ambiente social de los personajes que tratan de sobrevivir como pueden” (Reynaert: 2008).

\subsubsection{El niño de la bicicleta que busca vínculo}

Al igual que Rossellini con Alemania, año cero (Germania, anno zero, 1948), Truffaut con Los cuatrocientos golpes (Les 400 coups, 1959) y El pequeño salvaje (L'enfant sauvage, 1970) y Maurice Pialat con L'enfance nue (1968), los hermanos Dardenne, más tarde o temprano, tenían que rodar una película de "infancia problemática”. Efectivamente, Cyril, el protagonista de El niño de la bicicleta (Le gamin au veló, 2011), a pesar de ser un chico del siglo XXI, está emparentado con Edmund, Antoine, Victor y François, pero también, como ha indicado Sáez (2012) en su análisis de la obra "dardenniana", con Billy en la película Kes (1969) de Ken Loach y con Paul en Pure (2002) de Gillies Mackinnon; y así mismo, podríamos añadir, visitando otros continentes fílmicos, con el chico indio de Salaam Bombay (1988) de Mira Nair y con la "niña de la calle" colombiana en La vendedora de rosas (1998) de Víctor Gaviria, pues, al fin y a la postre, el imaginario cinematográfico relacionado con las infancias difíciles nos ha proporcionado obras de bastante entidad.

Cyril es, como la mayoría de los personajes mencionados anteriormente, un muchacho a la búsqueda desesperada del vínculo paterno, el único que cree 
poseer todavía al inicio de la trama. Nada ni nadie logra convencerle de que su padre ha decidido marcharse e interrumpir su relación con él.

Con la ayuda de Samantha, la peluquera que ha conocido huyendo de los educadores de su escuela de acogida, el chico logra encontrarle, pero ni siquiera cuando sea el propio padre quien le diga que no intente verle nunca más y que se quede con la mujer, podrá asumirlo. ¿Acaso un niño de doce años puede comprender que, en realidad, representa un serio obstáculo para la "nueva vida" de su padre? Por eso, trata de encontrar una figura paterna sustitutiva y cree haberla hallado en un joven traficante, para el cual perpetra un robo con violencia. Aunque después, y montado en su única "válvula de escape”, su bicicleta, emprende su último intento yendo a entregar al padre el dinero robado. El rechazo paterno es entonces total y el chico empieza a comprender la dura realidad. Será Samantha, probablemente el primer protagonista positivo de los Dardenne, quien finalmente restablezca un vínculo afectivo con Cyril.

\section{Planos cortos y de larga duración: documentos vivos de personajes marginados}

Este final abierto, pero "más feliz" que los de sus largometrajes anteriores, ha sido objeto de variados comentarios de todo tipo. Pero, no cabe duda de que se trata de una opción bien meditada por parte de los cineastas, de ahí que, no sólo han elegido por vez primera a una actriz consagrada para este personaje luminoso, sino que denotamos también la presencia de la música como recurso expresivo. Según los hermanos, el amor de la protagonista es el que hace que surja, como si fuese una "caricia latente", el adagio del concierto número 5 para piano de Beethoven. En este su regreso a Seraing, también existen novedades en el aspecto formal. Aquí, la cámara se mueve, en general, mucho menos que en los filmes anteriores, pues no se trata aquí de acechar los movimientos del conturbado protagonista, como en el caso de Rosetta u Olivier, sino de observar su soledad, su energía vital y también su espera, su deseo de encontrar a alguien. Además, Cyril está casi siempre en primer plano con la cámara a su altura, de forma que muchos sonidos nos 
llegan en off. O bien está solo en el plano o, si está acompañado, es porque los demás personajes se encuentran cerca de él. En tales casos, además, los adultos aparecen “cortados” en el encuadre. Una vez más, nos interesa reforzar esta idea sobre la gramática dardeanna adentrándonos en una de las escenas más significativas de la película.

Lo argumentado podemos observarlo nítidamente en una secuencia fundamental: la del restaurante donde el padre se reúne con su hijo, que acaba de llegar con Samantha. En ella, los hermanos Dardenne demuestran un especial virtuosismo en la filmación. Primero, con el chico hablando y siguiendo las evoluciones del padre. Luego, en la conversación entre éste y Samantha, uno de los pocos momentos de la película en que el niño no está presente. Es esta una escena donde los personajes se mueven dentro del plano para que, de manera natural, y sin necesidad de cortes como suele hacerse habitualmente, se produzca el plano y el contraplano. Así, al principio cuando ella pide al padre que se ocupe del chico, la mujer está a la izquierda, frente al objetivo y el padre, enfrente de ella, casi de espaldas al mismo. El personaje masculino se encuentra, en ese momento, psicológicamente atrapado por las preguntas que le hace la peluquera. Luego, los actores (Jérémie Renier, de nuevo incorporando a un padre que niega su vínculo biológico, y Cécile de France) se giran casi imperceptiblemente, de manera que ahora, cuando el padre confiesa a la peluquera que no puede hacerse cargo del chico y que estaría mejor con ella, Samantha sigue a la izquierda, pero ahora de espaldas a la cámara y el progenitor continúa a la derecha, pero casi de frente al objetivo.

Las películas de ficción de los hermanos Dardenne son documentos vivos, caracterizados por un realismo descarnado, poblados de personajes marginales y excluidos, con una cámara que los capta con un humanismo sutil y profundo, en consonancia con el punto de vista que adoptan los directores en cada caso para contarnos sus peripecias vitales, colocando siempre al espectador en una posición protagonista, más allá de la típica de mero observador. Su estilo característico viene dominado por los planos cortos y de larga duración para que podamos seguir atentamente la acción, 
sintiéndonos testigos privilegiados de la misma. Este sello personal se siente también en la trama que nos cuentan, inserta siempre en una base documental que nos obliga a mirar hacia nosotros mismos. Su personaje protagonista (Igor, Rosetta, Olivier, Bruno, Lorna, Cyril) se encuentra siempre ante un conflicto interno, un dilema moral que, aunque nunca logra resolver, le obliga a dar un giro importante en su trayectoria vital.

En unas declaraciones de 2005, los Dardenne hablaban de que elegían a los desheredados como protagonistas de sus filmes porque no son visibles. Su retrato fílmico lo realizan desde el afecto y no desde la piedad, sabiendo que muchos de sus personajes son el espejo angustioso que han dejado los rescoldos de todas esas operaciones especulativas en que ellos, y a la postre todos nosotros, somos solamente un número o, peor aún, formamos parte del extraño porcentaje de "irremediables víctimas" de ese eufemismo llamado crisis. A estos seres socialmente relegados, "nadie los mira de una manera real, nadie ve sus sueños, su amor, y por eso nos gusta hablar de ellos" (Balbuena: 2005). Como refiere Erner (2006: 8), "mucho tiempo enmudecidas, las víctimas reclaman ahora un reconocimiento, tratamientos particulares e, incluso, reparaciones”. El universo cinematográfico de los hermanos Dardenne es una de las más preclaras muestras de este reconocimiento. Por todo ello, sus películas ofrecen enormes posibilidades para reflexionar, desde múltiples instancias educativas y sociales, sobre este mundo que nos ha tocado vivir: los mismos hermanos tenían una visión pedagógica de su obra. En una entrevista realizada por Marceau Verhaege (2004: 2, 5) a Jean- Pierre Dardenne sobre los talleres impulsados en Dérives por ellos, éste contesta:

"Pronto fuimos reconocidos como organismo de educación permanente pues nuestros films formaban parte de un trabajo más ambicioso en los comités obreros, en la casa de juventud, en las asociaciones de barrio... Desde nuestro taller comenzamos a apoyar a otros cineastas. Es una manera de ayudar a quienes quieren decir cosas que les apasionan y les interesan (...). Sin querer ser una escuela, Dérives puede ser también un banco de aprendizaje”. 


\section{A modo de sugerencias para la investigación}

La obra de los Dardenne ofrece multitud de estímulos para la búsqueda y la investigación de toda una serie de temas, muchos de los cuales tan solo aquí han sido apuntados. Desde el punto de vista evolutivo, el historiador tiene la oportunidad de hallar anclajes profundizando en esa tradición en la que los Hermanos se encuentran cómodos, de tal modo que si en nuestro primer apartado, construido a fuerza de brochazos impresionistas, nos decantábamos por la sugerencia, a partir de la comparación con la obra de Bresson, Renoir, Rossellini, Loach o ,por ejemplificar con otro gran autor más, un determinado Truffaut, se encuentran toda una serie de posibilidades para comparar la obra de nuestros directores belgas con aquellos que más le influenciaron, en propias palabras. Los Dardenne son de esa clase de creadores que reflexionan constantemente sobre sus productos y buscan las huellas de quienes se encuentran cerca de sus postulados o, por el contrario, se distancian de ellos, lo que también es objeto de interés investigador.

En esta misma dirección de pensamiento se encuentra la preocupación humanista de los Dardenne por la ética. También este tema ha sido apuntado en nuestras páginas. Conocido es que los autores de "El hijo" o "El silencio de Lorna" evocaron directamente a Levinas para hacer referencia a la preocupación por el otro. "El hijo" ha dado lugar a varias lecturas, siendo la ética y la pedagógica las que nos llaman más la atención por el juego que las obras de Luc y Jean-Pierre ofrecen al investigador que quiera ahondarlas desde estos puntos de vista. Schujman e Iglesias (2013), sirviéndose de pensadores como Bauman y Levinas apuestan por conjugar ambas: "Nosotros optamos por las dos. Una centrada en la acción ética, entendida como acción no racional en un contexto de ambivalencia donde aparece la incertidumbre como condición del sujeto moral. La otra centrada en lo pedagógico, en el acto de educar, donde también el adulto se responsabiliza ante el niño"(2003: 1). En estos campos de conocimiento queda mucho por explorar si se relacionan con el cine. El trabajo de Sarah Cooper (2007: 66-87) parte de las propias declaraciones que los hermanos han hecho con frecuencia, 
refiriéndose al filósofo Levinas, para relacionar la ética propuesta por el pensador y las continuas alusiones que en su diario, “ Detrás de nuestras imágenes", los realizadores reconocen. Luc Dardenne cita a Levinas ("La vida espiritual es esencialmente vida moral y su lugar de predilección es lo económico. Esta constante de Levinas es también la de nuestro cine”) para reforzar y dar sostén teórico a sus propuestas fílmicas, tanto en el contenido como en la forma de conducirlo. Este planteamiento le permite a Sarah Cooper interpretar la obra de los Dardenne desde prismas éticos al considerar que sus films significan "una reformulación de la ética como filosofía primera en la realización de los mismos" (2007: 85). Esta afirmación sintetiza la posición de Cooper y su complejo análisis. Ya que por una parte, para ella, no toda la obra de los Dardenne se puede interpretar en clave levinasiana -"en sus films el ángulo de filmar el cuerpo no encarna literalmente la orientación ética de Levinas" (Cooper, 2007: 74)- y ,por otra la ética y las metas globales de su cine se aúnan en un todo unitario, congruente y sólido.

"Los Dardenne impulsan un movimiento pionero en el cine, lejos de las discusiones, lejos de las discusiones teóricas sobre el pensamiento y el cuerpo, mediante la ubicación de la película más cerca de la concepción del alma humana, en términos de Levinas, que del cuerpo o la mente” (Cooper, 2007: 77).

En el diario, L. Dardenne manifiesta su sentido iconoclasta cuando hace referencia repetida a su "deseo de cambiar lo habitual, las imágenes cliché del cine": ¿podríamos proyectar una imagen tan vulnerable e intensa que fuera como el rostro del otro más allá de su plástica?” (2005: 29). ”Las imágenes de nuestros films, ¿pueden provocar una falla, un agujero en lo que es?"(2005: 108). Como afirma S. Cooper, los films de los Dardenne realizan un "reto de inspiración levinasiana para transformar el ser del cine” (2007: 66). Ya Fabien Marsella ponía el acento de su análisis en recordarnos que " el arte de hacer " de los Dardenne tiene que remitirse, para entender bien su trabajo, al "mérito de insistir sobre el rechazo de un uso erudito, virtuoso del cine", que huye de una concepción rígida de método que "sea aplicado de modo 
indiferente y uniformemente a cada film", distanciándose de "toda técnica pesada y artificial" que condicione el resultado último del producto" (2008: 1). Los Dardenne no trabajan en clave de expertos sino que su plataforma de apoyo es partir de lo real, tal y como es percibido por ellos para ir construyendo el edificio fílmico. Una constante que, como repetidamente se ha formulado en nuestros apartados anteriores, seducen a los directores orientados por esa idea de hacer un cine diferente al consumista comercial.

La adjetivación que Flamant formulaba para definir a los Hermanos Dardenne, "un equipo de oro" (Marsella, 2008: 3) confirma las declaraciones de los directores belgas quienes insisten en que "el trabajo en equipo es la ausencia de posición de autor "ya que la creación a dos es consustancial a su cine” (Marsella, 2008). Los Dardenne, siempre prestos a cuestionarse, son partidarios de cuidar la etapa más importante de creación, el rodaje, porque durante él y la libertad que ellos conceden a sus actores, "debe suceder alguna cosa que no estaba prevista”. Un ejemplo evidente de la ética de este dúo de cineastas que promueven una obra tan singular en sus lenguajes como comprometida en sus contenidos y formas de narrar.

\section{Referencias bibliográficas}

BADIOU, Alain (2004). "El cine como experimentación filosófica". En YOEL, Gerardo (Coord.) Pensar el cine: imagen, ética y filosofía. B. Aires: Edit. Manantial.

BALBUENA, Camino (2005). "Retazos de realidad. Crítica en torno a $E l$ niño". En www.http://contrapicado.net/old/critica.php?id=89 Disponible en Marzo de 2013.

BÉGAUDEAU, François (2005). "L’Enfant de Luc et Jean-Pierre Dardenne“. En Cahiers du Cinéma, n 605, Octubre, pp. 24-26.

BISSIÉRE, M Michèle (2013). "De la promise a l'enfant : le cinéma éthique de les fréres Dardenne“. En http:/www languages.uncc.edu/.../ michèle-bi. Disponible en marzo de 2013.

CARDULLO, Bert (2009). Committed cinema: the films of Jean-Pierre and Luc Dardenne; essays and interviews. Newcastle: Cambridge Scholars Publishing.

CHAUVIN, Jean-Sébastien (2002). "Métaphysique chimie“. En Cahiers du Cinéma, 572, Octubre, pp. 80-81.

CAMPILLO, Margarita y ZAPLANA, Andrés (2007). "La pedagogía hecha cine $o$ el cine hecho pedagogía“. En GARCIA, Alfonso Y 
ESCARBAJAL, Andrés (Coords.) Infancia, cine y educación. Murcia: Diego Marin Editores, pp.93-116.

CAMPILLO, Margarita (2012). La escuela como espacio de construcción ética y de investigación en valores: la educación para la paz a través del cine de guerra en la Enseñanza Secundaria. Programa III del Convenio de cooperación en materia de Formación Inicial y Permanente del profesorado, entre la Universidad de Murcia y la Consejería de Educación, Formación y Empleo. Murcia: ICE.

COOPER, Stephen (2007). "Morthal ethics: Reading Levinas with the Dardenne Brothers". En Film-Philosophy, v.11, n. 2, pp. 66-87. http:/www.film-philosophy.com/2007v11n2/cooper.pdf. Disponible en Marzo de 2013.

DARDENNE, Luc (2005). Au dos de nos images, 1995-2005. París: Edit. Seuil (versión castellana de 2006 con el título Detrás de nuestras imágenes. Madrid: Plot).

ERNER, Guillaume (2006). La societé des victimes. Paris: Editions La Decouverte.

FERNÁNDEZ, Ángel (1997). "Pozo negro en Europa”, El País, 11 de Febrero, en: http://elpais.com/1997/o2/11/cultura/855615612_850215.html Disponible en Marzo de 2013.

FERNANDEZ, Ángel (2002). "Un mundo de locura y verdad”, El País, 6 de Diciembre, en http://elpais.com/diario/2002/12/06/1039129213 _850215.html Disponible en Marzo de 2013.

GARCÍA, Alfonso et alt (2007). "La promesse: una invitación a reflexionar sobre la vida cotidiana de los inmigrantes". En GARCIA, Alfonso y ESCARBAJAL, Andrés (Coords.) Infancia, cine y educación. Murcia: Diego Marin Editor, pp.11-36.

GUBERN, Roman (1989). Historia del cine. Barcelona: Lumen.

GUFFANTI, Gastón (2013). "Realismo a la belga”. En http://www.arte criticas.com.ar/detalle.php? $\mathrm{id}=346 \& \mathrm{c}=5 \& \mathrm{t}=2$. Disponible en marzo de 2013.

IMBERT, Gerard (2010). Cine e imaginarios sociales. Madrid: Cátedra.

LALANNE, Jean-Marc (1996). "Histoire de l'ogre“. En Cahiers du cinéma, 506, pp. 40-43.

LE GENISSEL, Aurélien (2010). "Dostoievski en Lieja“. En Dirigido por 399, Abril, pp. 40-41.

LE GENISSEL, Aurélien (2011). “Los Dardenne se ‘desmelenan”. En Dirigido por, Octubre, pp. 28-29.

LOSILLA, Carlos (2000). "Rosetta. El cine que viene“. En Dirigido por, 286, Enero, p. 10.

MAI, Joseph (2010). Jean-Pierre and Luc Dardenne. Urbana: University Illinois Press.

MAIRLOT, Madeleine (2005). Il était une fois. Rosetta la crise dans l'œuvre de Luc et Jean-Pierre Dardenne en général, et dans Rosetta en particulier. Liège: Ed. Du Cefal. 
MARSELLA, Fabien (2008). "Le silence de Lorna (2008) de Luc et Jean Pierre Dardenne“. En http://www.cndp.fr/crdplyon/IMG/pdf/Le Silence de Lorna_FM.pdf Disponible en Marzo de 2013.

MARTINEZ MALAGELADA, Clara (2012). "El niño de la bicicleta. Coloquio con los hermanos Dardenne". En Sala 1 http://revistasala1.com/ 2012/10/30/encuentros-en-la-filmoteca/

RIAMBAU, E. (1997). "La promesa. Artificio y realidad“. En Dirigido por 254, Febrero, p. 9.

QUINTANA, Ángel (2002). "Duelo y redención“. En Dirigido por 318, Diciembre, pp. 32-33.

REYNAERT, Matthieu (2008). "Entrevista a los hermanos Dardenne sobre El silencio de Lorna. En http://cineuropa.org/ff.aspx?t= ffocusinterview\&l=es\&tid $=1587 \&$ did $=85557$.

RANCIÈRE, Jacques (1999). "Le bruit du people, l'image de l' art (A propos de Rosetta et de L'Humanité)“. En Cahiers du cinéma, 540, Noviembre, pp. 110-112.

SÁEZ, Juan (2012). Cyril o la búsqueda de vínculo. En GARCIA, José (coord.), Pensar, mirar, exponerse. Valencia: Nau Llibres, pp. 113126.

SAEZ, Juan, ZAPLANA, Andrés y CAMPILLO, Margarita (2007). "Korczak o la lucha por la infancia”. En GARCIA, Alfonso y ESCARBAJAL, Andrés (coords.) Infancia, cine y educación. Murcia: Diego Marin Editores, pp. 93-116.

SCHUJMAN, Gustavo, IGLESIAS, Patricia. "El hijo. Un debate sobre la dimensión ética”. En http://www.buenosaires.gob.ar/areas/ educacion/cepa/el_hijo.pdf. Disponible en Marzo de 2013.

VERHAEGE, Marceau. "L'atelier des fréres Dardenne, Dérives“. En (http://www.cinergie.be/webzine/dossier_ateliers_derives_asbl)

Disponible en marzo de 2013.

ZAPLANA, Andrés (2005). Entre pizarras y pantallas: profesores en el cine. Badajoz: Diputación Provincial de Badajoz.

\section{Videografía}

La promesa (La promesse, 1996). Colección Vértigo.

Rosetta (1999). Manga Films.

El hijo (Le fils, 2002). S.A.V. De APlaneta-Vértigo.

El niño (L'enfant, 2005). Vértigo.

El "home cinema" de los hermanos Dardenne (Jean-Pierre Limosin, 2006).

Intermedio.

"Dans l'obscurité" en Chacun son cinema (2007). Pyramide distribution (Francia).

El silencio de Lorna (Le silence de Lorna, 2008). A.V.H.

El niño de la bicicleta (Le Gamin au vélo, 2011). Cameo. Wanda Visión. 